\title{
Relation of midwall circumferential systolic stress to equatorial midwall fibre shortening in chronic aortic regurgitation \\ Value as a predictor of postoperative outcome
}

\author{
PEDRO ALMEIDA, MANUEL CÓRDOBA, JAVIER GOICOLEA, ROSANA HERNÁNDEZ \\ ANTOLÍN, LUIS A RICO, MANUEL REY, PEDRO RÁBAGO, GREGORIO RÁBAGO \\ From the Departments of Cardiology and Cardiovascular Surgery, Fundación Fiménez Diaz, Madrid, Spain
}

SUMMARY Nineteen patients with chronic aortic regurgitation and a large increase in heart size were studied before aortic valve replacement. By relating midwall circumferential systolic stress to midwall circumferential fibre shortening $(\mathrm{Cs} / \mathrm{Cd})$ before operation the patients could be divided into two well defined groups. Twelve patients (group 1) had a pronounced decrease in heart size as measured by the cardiothoracic ratio and an excellent clinical outcome six months after operation. Seven patients (group 2) had no significant decrease in heart size and a less good clinical outcome. The ratio of midwall circumferential systolic stress to end systolic volume index was significantly higher in group 1 than in group 2. Group 2 had more severe left ventricular hypertrophy determined by the ratio of the wall thickness to the minor internal radius of the left ventricle (h:r ratio), total left ventricular mass, and left ventricular mass to end diastolic volume ratio. There were no significant differences in any other haemodynamic or angiographic indices between the two groups.

Thus the relation of midwall circumferential systolic stress to fibre shortening is useful in determining the prognosis in individual patients with chronic aortic regurgitation undergoing aortic valve replacement.

The prognosis of individual patients with chronic aortic regurgitation undergoing aortic valve replacement remains one of the more perplexing problems in modern cardiology. In some instances, it seems likely that long standing volume overload leads to irreversible left ventricular dysfunction irrespective of the clinical status.' Many studies have analysed preoperative left ventricular function in chronic aortic regurgitation ${ }^{2-7}$ in an attempt to identify patients who are at high risk of dying of congestive heart failure during the longterm postoperative course. On the other hand, patients undergoing aortic valve replacement whose cardiac enlargement does not decrease after operation have a less good postoperative outcome than those

Requests for reprints to $\operatorname{Dr}$ M Córdoba Polo, Laboratorio de Hemodinámica, Servicio de Cardiología, Fundación Jiménez Diaz, Pza Cristo Rey 2, Madrid, Spain.

Accepted for publication 15 May 1984 who have an appreciable reduction in cardiomegaly. ${ }^{8-10}$

In the present study we used a new approach for the preoperative analysis of patients with chronic aortic regurgitation by applying a stress-strain analysis of left ventricular contraction to identify those patients with irreversible left ventricular dysfunction. We compared the results with the postoperative variations in heart size measured by the cardiothoracic ratio six months after operation.

\section{Patients and methods}

PATIENT SELECTION

Fifty five out of 84 patients with pure aortic regurgitation (peak systolic aortic gradient $<15 \mathrm{~mm} \mathrm{Hg}$ ) in whom haemodynamic studies had been performed in our laboratory from January 1977 to June 1980 underwent aortic valve replacement. Of these, we selected 19 patients who had pronounced cardiomeg- 
aly on the routine chest $x$ ray film (mean cardiothoracic ratio 0.62 ; range $0.57-0.70$ ). Of these 19 patients, 18 were clinically evaluated six months after operation; the patient in case 19 died $\mathbf{4 5}$ days after the operation as a result of congestive heart failure. We excluded patients who had acute aortic regurgitation on clinical and surgical grounds. Of the 19 patients, six were women and 13 men (mean age 38 (range 24-59) years). Six patients were asymptomatic and 12 had symptoms in NYHA functional class II, of whom five had exertional angina. One patient had symptoms in NYHA functional class IV. All patients showed left ventricular hypertrophy in the electrocardiogram, 16 were in sinus rhythm, three had chronic atrial fibrillation, and two had previously documented transient episodes of atrial fibrillation.

\section{CORONARY ARTERIOGRAPHY}

All patients underwent right and left cardiac catheterisation before operation. Coronary arteriography was performed in all male patients aged $\geqslant 45$ years (four patients) and in all patients whose presenting symptom was angina irrespective of sex and age (two patients). Pressures were recorded with external transducers (Stratham P-23 Db). Cardiac output was measured by thermodilution with the aid of a computer (E for $M$-Lyons TCCO-10). Left ventricular angiography was performed in the right anterior oblique position with the contrast medium (meglumine diatrizoate $66 \%$ ) injected at a mean speed of $17.5 \mathrm{ml} / \mathrm{s}$ through an NIH No $7 \mathrm{~F}$ or $8 \mathrm{~F}$ catheter. Films were taken at 50 frames/s, extrasystoles and postextrasystoles were excluded from analysis. In the three cases with chronic atrial fibrillation, the first four beats with good opacification were analysed.

Left ventricular volume was calculated by the arealength method. ${ }^{11}$ Magnification for volume and mass was corrected using a calibrated grid placed $10 \mathrm{~cm}$ above the plane of the table. ${ }^{12}$ Ejection fraction (EF) was calculated from the corrected volumes as follows: $\mathrm{EF}=\mathrm{EDV}-\mathrm{ESV} / \mathrm{EDV}$ where EDV is end diastolic volume and ESV end systolic volume. The regurgitant fraction (RF) was calculated as follows: $\mathbf{R F}=$ (angiographic stroke volume minus anterograde thermodilution stroke volume) divided by angiographic stroke volume. Left ventricular mass was calculated using the method of Trenouth et al. ${ }^{13}$ Left ventricular free wall was drawn in the middle third of the cardiac shadow at end diastole, and the resulting rectangle was measured by planimetry. The area divided by the length and corrected for radiographic magnification was taken as the mean end diastolic wall thickness (hd). On the basis that the left ventricular mass remains constant during cardiac contraction end systolic wall thickness (hs) was calculated as proposed by Hugenholtz et al. ${ }^{14}$ Left ventricular .internal diameters at end diastole (Dd) and end systole (Ds) were calculated by the area-length method.

In all cases, midwall circumferential systolic stress (MWCS) was determined using the equation of Mirsky ${ }^{15}: M W C S=p b / h \times\left(1-h / 2 b-b^{2} / 2 a^{2}\right)$, where $h$ is end systolic wall thickness, a end systolic midwall major semi-axis, b end systolic midwall minor semiaxis, and $p$ intraventricular peak systolic pressure, measured as the mean value of the 10 beats immediately preceding left ventricular angiography. We calculated the circumferential shortening of the equatorial midwall fibre as $\mathrm{Cs} / \mathrm{Cd}$, Cs being $=\mathrm{Ds}+\mathrm{hs}$ and $\mathrm{Cd}$ being $=\mathrm{Dd}+\mathrm{hd}$.

\section{AORTIC VALVE REPLACEMENT}

All patients were operated on within two months of cardiac catheterisation. Ten patients had a Hancock porcine heterograft and nine a Björk-Shiley prosthesis implanted. All patients underwent a complete clinical evaluation, which included a standard posteroanterior chest radiograph six months after operation.

\section{STATISTICAL ANALYSIS}

Values are expressed as means and standard deviations (SD). The least squares method for regression equations was used. The statistical analysis of the regression lines was performed by covariance analysis. Means of two samples were compared by Wilcoxon's rank sum test.

\section{Results}

HAEMODYNAMIC MEASUREMENTS

The individual values of midwall circumferential sys-

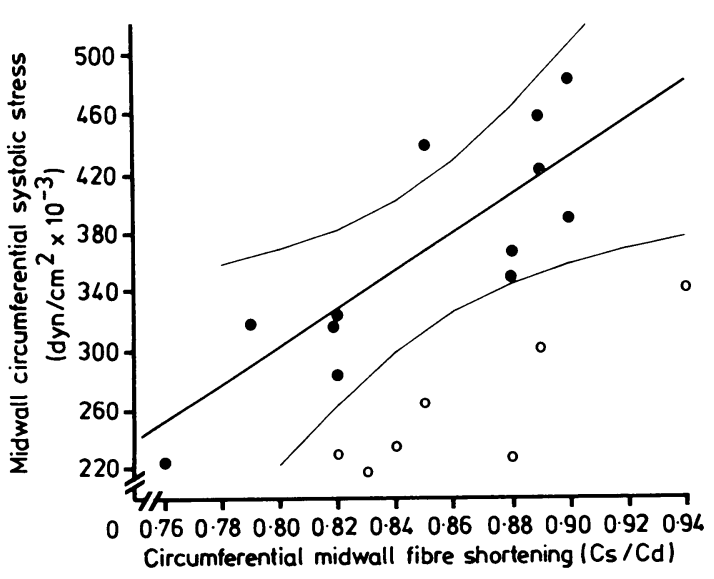

Figure Relation of midwall circumferential systolic stress to circumferential midwall fibre shortening $(C s / C d)$ in patients in group 1 (O) and group $2(\bigcirc)$. 
Table 1 Values for the midwall circumferential systolic stress (MWCS), midwall circumferential shortening (Cs/Cd) and MWCS/end systolic volume index (MWCS/ESVI) in 19 patients with chronic aortic regurgitation

\begin{tabular}{llll}
\hline Case No & $\begin{array}{l}M W C S \\
\left(d y n / \mathrm{cm}^{2} \times 10^{-3}\right)\end{array}$ & MWCS/ESVI & $C s / C d$ \\
& & Group 1 \\
1 & 319 & 6.25 & \\
2 & 458 & 4.62 & 0.79 \\
3 & 390 & 2.54 & 0.89 \\
4 & 225 & 2.88 & 0.90 \\
5 & 438 & 3.56 & 0.76 \\
6 & 367 & 2.54 & 0.85 \\
7 & 483 & 4.09 & 0.88 \\
8 & 319 & 2.38 & 0.90 \\
9 & 422 & 2.18 & 0.82 \\
10 & 319 & 4.08 & 0.89 \\
11 & 349 & 2.49 & 0.82 \\
12 & 285 & 5.48 & 0.88 \\
Mean(SD) & $364(76)$ & $3.59(1.33)$ & 0.82 \\
& & $0.85(0.045)$ \\
13 & 230 & Group 2 & \\
14 & 265 & 3.33 & 0.82 \\
15 & 235 & 2.10 & 0.85 \\
16 & 227 & 2.21 & 0.84 \\
17 & 217 & 2.60 & 0.88 \\
18 & 302 & 3.28 & 0.83 \\
19 & 342 & 1.97 & 0.87 \\
Mean(SD) & $259(44)$ & 1.44 & 0.94 \\
Significance & $\mathrm{p}<0.005$ & $2.41(0.69)$ & $0.86(0.039)$ \\
\hline
\end{tabular}

Table 2 Clinical features in 19 patients with chronic aortic regurgitation

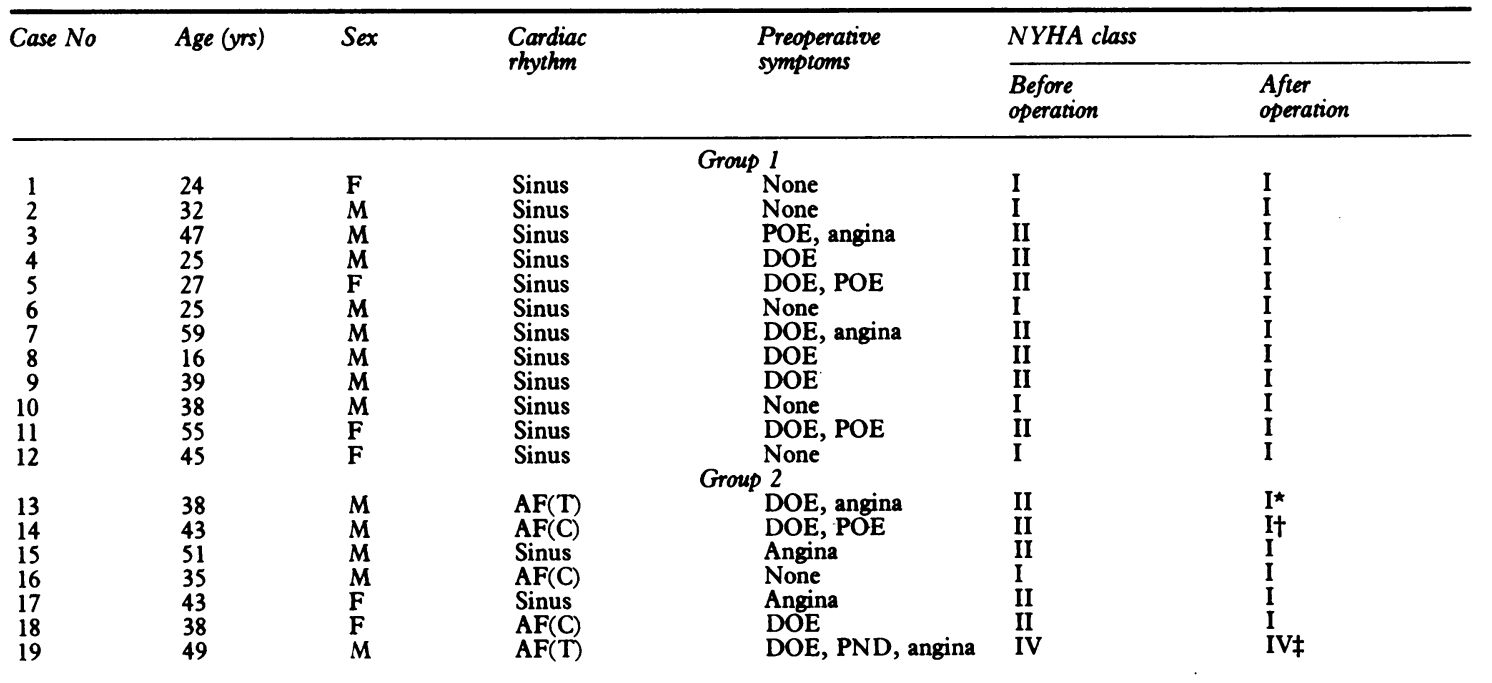

AF, atrial fibrillation (C, chronic; T, transient); DOE, dyspnoea on exertion; PND, paroxysmal nocturnal dyspnoea; POE, palpitations on exertion.

^Acute pulmonary oedema 42 months after operation.

†Died two years after operation.

$¥$ Died 45 days after operation. tolic stress and midwall circumferential fibre shortening were plotted, giving two different groups of data (Figure); 12 patients fell within the $95 \%$ confidence limits of the linear relation between the two measurements (group 1) and seven patients fell outside these confidence limits (group 2) indicating significantly lower midwall circumferential systolic stress for the same degree of midwall circumferential fibre shortening. A regression line was fitted to each group of data to give the following regression equations: $Y_{1}=$ MWCS $_{1}=1362(\mathrm{Cs} / \mathrm{Cd})_{1}-793 ;(\mathrm{r}=0.8389 ; \mathrm{p}<0.001)$ and $\mathrm{Y}_{2}=\mathrm{MWCS}_{2}=936(\mathrm{Cs} / \mathrm{Cd})_{2}-547 ; \quad(\mathrm{r}=0.8178$; $p<0.05)$. A covariance analysis of these regression lines showed a highly significant difference between them $\left(Y_{1} \neq Y_{2} ; p<0.001\right)$. Although the slopes of both regression lines were different, this difference did not reach the level of statistical significance $\cdot(0.05<\mathrm{p}<0.1)$

The individual data for each patient are shown in Table 1. The mean value of midwall circumferential systolic stress was significantly higher in group 1 than in group $2(\mathrm{p}<0.005)$. The mean value of $\mathrm{Cs} / \mathrm{Cd}$ was similar in both groups. The mean value of midwall circumferential systolic stress to end systolic volume index (MWCS/ESVI) for group 1 was higher than that for group $2(p<0.025)$. There was, however, a high degree of overlap between both groups for this value. 
Table 3 Changes in the cardiothoracic ratio six months after operation in 19 patients with chronic aortic regurgitation

\begin{tabular}{|c|c|c|}
\hline \multirow[t]{2}{*}{ Case No } & \multicolumn{2}{|c|}{ Cardiothoracic ratio } \\
\hline & Before operation & After operation \\
\hline & \multicolumn{2}{|c|}{ Group 1} \\
\hline 1 & 0.61 & 0.43 \\
\hline 2 & 0.60 & 0.52 \\
\hline 3 & 0.69 & 0.60 \\
\hline 4 & 0.57 & 0.50 \\
\hline 5 & 0.58 & 0.40 \\
\hline 6 & 0.69 & 0.47 \\
\hline 7 & 0.62 & 0.52 \\
\hline 8 & 0.63 & 0.51 \\
\hline 9 & 0.65 & 0.55 \\
\hline 10 & 0.57 & 0.49 \\
\hline 11 & 0.62 & 0.48 \\
\hline 12 & 0.61 & 0.53 \\
\hline Mean(SD) & $0.62(0.038)^{\star}$ & $0.50(0.051) \ddagger$ \\
\hline Significance & \multicolumn{2}{|c|}{$\begin{array}{l}\mathrm{p}<0.001 \\
\text { Group } 2\end{array}$} \\
\hline 13 & 0.63 & 0.61 \\
\hline 14 & 0.57 & 0.56 \\
\hline 15 & 0.59 & 0.59 \\
\hline 16 & 0.65 & 0.65 \\
\hline 17 & 0.65 & 0.58 \\
\hline 18 & 0.70 & 0.70 \\
\hline 19 & 0.62 & - \\
\hline Mean(SD) & $0.63(0.042)+$ & $0.61(0.051)$ \\
\hline Significance & \multicolumn{2}{|r|}{ 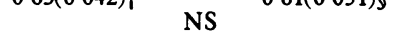 } \\
\hline
\end{tabular}

*Compared with $t$, NS

$\ddagger$ Compared with $\oint, \mathrm{p}<0.001$.

\section{CLINICAL DATA}

Table 2 shows the clinical data for both groups of patients. Mean age in both groups was not significantly different ( 36 (13) years vs $42(5.9)$ years; $\mathrm{p}>0.05)$. There were seven symptomatic patients $(58 \%)$ in group 1 and six in group $2(85 \%)$. All patients were asymptomatic six months after operation, except one patient in group 2 whose symptoms remained in NYHA functional class IV after operation and who died 45 days later. All patients in group 1 were in sinus rhythm, whereas three patients in group 2 had chronic atrial fibrillation and two others transient episodes of atrial fibrillation.

\section{POSTOPERATIVE VARIATION IN HEART SIZE}

There was a pronounced difference between the two groups in the reduction of the cardiothoracic ratio after operation (Table 3). There was no difference between both sets of preoperative values. Group 1 showed a pronounced reduction in cardiothoracic ratio six months after operation giving a normal value in all patients but one (case 3 ), who had a $13 \%$ reduction, which did not reach the normal value of 0.55 . The mean postoperative ratio in group 1 was significantly less than the mean preoperative value $(p<0.001)$. The mean decrease was $15 \%$ for this group as a whole.

In contrast, patients in group 2 did not show any significant change in ratio six months after operation.
Only the patient in case 17 had a decrease of $10 \%$, which was less than any of those in group 1 and not enough to normalise the cardiothoracic ratio.

\section{HAEMODYNAMIC AND ANGIOGRAPHIC DATA}

Table 4 shows the haemodynamic and angiographic data of both groups. Aortic pressures did not show any significant differerice. Left ventricular end diastolic pressure (LVEDP) was increased in both groups to a similar extent and showed a wide scattering of values. The mean values for cardiac output and cardiac index were slightly higher in group 1 than in group 2, the differences not being significant. The mean values for end diastolic volume and end systolic volume were appreciably increased in both groups, with no significant differences. The regurgitant fraction was smaller in group 1, but the difference was not significant. The ejection fraction showed a mean value which was equally depressed in both groups.

\section{LEFT VENTRICULAR HYPERTROPHY}

Table 5 shows the values for the ratio of the wall thickness to the minor internal radius of the left ventricle ( $h: r$ ratio) and left ventricular mass to end diastolic volume ratio. Both were significantly higher in group $2(p<0.005)$ and $(p<0.005)$. The same was true for the total left ventricular mass and left ventricular mass index, both values being greater in group 2 $(\mathrm{p}<0.025)$ than in group $1(\mathrm{p}<0.025)$.

\section{MORTALITY DATA}

The mean follow up period after operation was similar for both groups of patients (23.9 months in group 1 vs 22.7 months in group 2). During follow up, there were no deaths in group 1 and two in group 2. The patient in case 14 (group 2) had several hospital admissions after operation because of ventricular arrhythmias; he died suddenly two years after operation. The patient in case 19 died 45 days after operation because of congestive heart failure. The patient in case 13 showed a pronounced clinical improvement six months after operation, remaining in stable clinical condition for 42 months, after which he was readmitted because of acute pulmonary oedema. Catheterisation at that time showed a normally functioning aortic prosthesis with no improvement in left ventricular systolic function and no decrease in end diastolic volume.

\section{Discussion}

The postoperative outcome of patients with chronic aortic regurgitation depends mainly on the existence, or absence, of irreversible preoperative left ventricular dysfunction. The preoperative diagnosis of this condition is still a major problem. The patient's clini- 
Table 4 Haemodynamic and angiographic data in 19 patients with chronic aortic regurgitation

\begin{tabular}{|c|c|c|c|c|c|c|c|c|c|}
\hline $\begin{array}{l}\text { Case } \\
\text { No }\end{array}$ & $\begin{array}{l}B S \\
\left(m^{2}\right)\end{array}$ & $\begin{array}{l}A o P \\
(m m H g)\end{array}$ & $\begin{array}{l}L V E D P \\
(m m H g)\end{array}$ & $\begin{array}{l}\text { CO } \\
(l / \min )\end{array}$ & $\begin{array}{l}C I \\
\left(l / m i n \text { per } m^{2}\right)\end{array}$ & $R F$ & $\begin{array}{l}E D V \\
(m l)\end{array}$ & $\begin{array}{l}E S V \\
(m l)\end{array}$ & $E F$ \\
\hline $\begin{array}{l}1 \\
2 \\
3 \\
4 \\
5 \\
6 \\
7 \\
8 \\
9 \\
10 \\
11 \\
12 \\
\text { Mean(SD) }\end{array}$ & $\begin{array}{l}1.45 \\
1.62 \\
1.68 \\
1.85 \\
1.52 \\
1.92 \\
2.04 \\
1.40 \\
1.83 \\
1.78 \\
1.81 \\
1.56\end{array}$ & $\begin{array}{l}108 / 40 \\
165 / 73 \\
185 / 36 \\
112 / 42 \\
160 / 60 \\
106 / 40 \\
158 / 54 \\
128 / 50 \\
144 / 52 \\
135 / 55 \\
108 / 63 \\
203 / 75 \\
142(32) / 53(11)\end{array}$ & $\begin{array}{r}43 \\
5 \\
6 \\
22 \\
1 \\
15 \\
44 \\
30 \\
7 \\
9 \\
25 \\
7 \\
17 \cdot 8(14)\end{array}$ & $\begin{array}{l}2 \cdot 90 \\
7 \cdot 55 \\
6 \cdot 16 \\
4 \cdot 88 \\
4 \cdot 63 \\
4 \cdot 80 \\
\overline{3} .10 \\
4 \cdot 40 \\
5 \cdot 80 \\
3 \cdot 39 \\
4.76(1.45)\end{array}$ & $\begin{array}{c}\text { Group } 1 \\
2.0 \\
4.6 \\
3.6 \\
2.6 \\
3.0 \\
2.5 \\
\overline{2.2} \\
2.4 \\
\overline{3.2} \\
2.1 \\
2.8(0.8) \\
\text { Grout 2 }\end{array}$ & $\begin{array}{l}0.66 \\
0.21 \\
0.42 \\
0.68 \\
0.50 \\
0.60 \\
\overline{0.74} \\
0.62 \\
\overline{0.48} \\
0.37 \\
0.52(0.16)\end{array}$ & $\begin{array}{l}164 \\
251 \\
408 \\
371 \\
303 \\
424 \\
321 \\
328 \\
495 \\
285 \\
378 \\
172 \\
325(98)\end{array}$ & $\begin{array}{l}74 \\
161 \\
258 \\
146 \\
187 \\
278 \\
241 \\
188 \\
354 \\
140 \\
254 \\
82 \\
196(83)\end{array}$ & $\begin{array}{l}0.55 \\
0.35 \\
0.36 \\
0.60 \\
0.38 \\
0.34 \\
0.24 \\
0.42 \\
0.28 \\
0.50 \\
0.33 \\
0.52 \\
0.40(0.11)\end{array}$ \\
\hline $\begin{array}{l}13 \\
14 \\
15 \\
16 \\
17 \\
18 \\
19 \\
\text { Mean(SD) } \\
\text { Significance }\end{array}$ & $\begin{array}{l}1.96 \\
1.80 \\
1.62 \\
1.69 \\
1.60 \\
1.47 \\
1.58\end{array}$ & $\begin{array}{l}130 / 80 \\
150 / 70 \\
180 / 50 \\
104 / 40 \\
124 / 54 \\
127 / 47 \\
180 / 70 \\
142(29) / 58(14) \\
\text { NS/NS }\end{array}$ & $\begin{array}{l}10 \\
16 \\
28 \\
8 \\
3 \\
12 \\
45 \\
17 \cdot 4(14) \\
\text { NS }\end{array}$ & $\begin{array}{l}3 \cdot 77 \\
4 \cdot 50 \\
3 \cdot 90 \\
4 \cdot 40 \\
4 \cdot 00 \\
3 \cdot 80 \\
4 \cdot 00 \\
4 \cdot 05(0 \cdot 28) \\
\text { NS }\end{array}$ & $\begin{array}{l}1.9 \\
2.5 \\
2.4 \\
2.6 \\
2.5 \\
2.5 \\
2.5 \\
2.4(0.23) \\
\text { NS }\end{array}$ & $\begin{array}{l}0.69 \\
0.68 \\
0.68 \\
0.32 \\
0.43 \\
0.53 \\
0.77 \\
0.58(0.16) \\
\text { NS }\end{array}$ & $\begin{array}{l}266 \\
408 \\
368 \\
238 \\
198 \\
336 \\
520 \\
333(110) \\
\text { NS }\end{array}$ & $\begin{array}{l}136 \\
228 \\
173 \\
148 \\
106 \\
225 \\
375 \\
198(89) \\
\text { NS }\end{array}$ & $\begin{array}{l}0.48 \\
0.44 \\
0.53 \\
0.37 \\
0.46 \\
0.33 \\
0.28 \\
0.41(0.08) \\
\text { NS }\end{array}$ \\
\hline
\end{tabular}

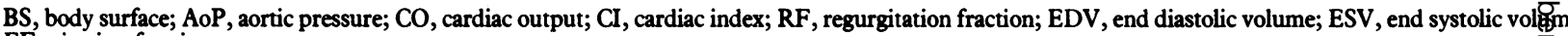
EF, ejection fraction.

Table 5 Left ventricular hypertrophy data in 19 patients with chronic aortic regurgitation

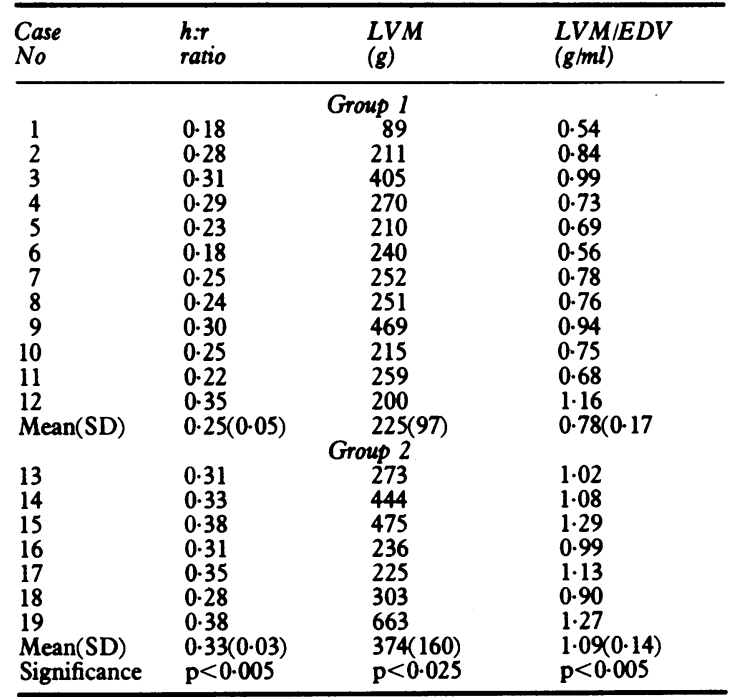

EDV, end diastolic volume; $h$, wall thickness of the left ventricle; LVM, left ventricular mass; $r$, minor internal radius of the left ventricle.

cal status is of no help. Not all of those with heart failure before operation have a poor outcome after operation. On the other hand, the absence of symptoms does not automatically rule out the existence of left ventricular dysfunction, as several authors have shown. ${ }^{16-18}$ By definition, the postoperative outcome after successful operation is an excellent guide to the previous existence, or absence, of irreversible ventricular dysfunction. Several investigators ${ }^{8-10}$ have found that the persistence of left ventricular dilatation, as measured by echocardiography, is associated with a higher risk of developing heart failure after operation, even if the haemodynamic disturbance has been corrected successfully. There is also general agreement, with the exception of the observations of Toussaint et al,,$^{19}$ that the reduction in heart size takes place early, from two weeks to two months after operation with very slight changes up to 63 months later. ${ }^{8-102021}$ These studies validated earlier observations on the prognostic value of the change in the cardiothoracic ratio after operation, ${ }^{22} 23$ which related the lack of reduction to a poorer prognostic outcome. The present study supports these previous reports. Of a total of 19 patients, 12 (group 1) had an important reduction in cardiothoracic ratio six months after operation, and six (group 2) showed no significant change in this value. The different behaviour of the cardiothoracic ratio was associated with the poorer clinical outcome in group 2.

Once these different clinical outcomes had been established, the purpose of the present study was to identify any factor in the preoperative haemodynamic study that would be able to predict the reduction in heart size after operation. The usual haemodynamic and angiographic indices were poor predictors. There was no difference between both groups in left ventricular end diastolic pressure, cardiac output, cardiac index, or regurgitant fraction. The mean value of end 
diastolic volume and end systolic volume was greatly increased, and the ejection fraction depressed, showing a similar degree of left ventricular systolic dysfunction in both groups. It is usually believed that patients with normal left ventricular systolic function have an excellent postoperative outcome.' Conversely, those with systolic dysfunction preoperatively have an unpredictable and uncertain outcome. ${ }^{4}$ It has recently been suggested that the end systolic diameter measured with echocardiography is of prognostic value in determining the development of congestive heart failure in the long term after aortic valve replacement. ${ }^{824-26}$ Not all patients within this high risk group, however, have a poor postoperative outcome, as is shown by our results and those of other authors. ${ }^{27}$ It is fundamental, therefore, to establish preoperatively which of those patients in the high risk group have a reversible type of left ventricular dysfunction after operation.

Recently, Borow et al found that end systolic stress and percentage fractional shortening determined by non-invasive methods are inversely and linearly related and that this relation was highly sensitive to alterations in left ventricular inotropic state. ${ }^{28}$ Based on these findings, they suggested that this relation may be potentially useful in assessing intrinsic left ventricular contractile impairment in patients with valvular disease. We have tested this hypothesis in patients with chronic aortic regurgitation, although with some methodological differences when compared with Borow's study.

End systolic stress is calculated through the use of the end systolic pressure and the end systolic volume. The end systolic pressure is difficult to determine, requiring the simultaneous recording of left ventricular pressure and volume. This necessitates the use of high fidelity angiocatheters and this complex methodology would exclude this analysis from everyday use. One of our main purposes was to establish a method that could be used in ordinary practice. In addition, several investigators ${ }^{24}$ 29-31 have previously shown that the relation of end systolic pressure to end systolic volume behaves very similarly to that of peak systolic pressure and end systolic volume in the clinical setting, in such a way that the use of peak systolic pressure introduces numerical rather than fundamental differences. Thus it seems reasonable that the same holds true for the relation of end systolic stress and end systolic volume and that of the midwall circumferential systolic stress and end systolic volume because in the equation to calculate the stress all indices are the same, with the exception of pressure being substituted by end systolic pressure in one case and by peak systolic pressure in the other. In our stressshortening analysis, we referred shortening to the midwall equatorial fibre of the left ventricle. With left ventricular contraction the myocardium not only shortens but also thickens, and several models have been described for the thickening-shortening relation. ${ }^{3: 33}$ The midwall fibre is a theoretical construction which reflects the fibre shortening better than the internal left ventricular diameters. We normalised the end systolic circumference (Cs) by dividing it by the end diastolic circumference $(\mathrm{Cd})$. The resulting index $(\mathrm{Cs} / \mathrm{Cd})$ is dimensionless and has the characteristics of a strain, with the general formula $\mathrm{Lf} / \mathrm{Lo}$, where $\mathrm{Lf}$ is final length and Lo initial length. In addition, this index maintains a very simple relation with the most usual percentage fractional shortening $((\mathrm{Cd}-\mathrm{Cs}) /$ $\mathrm{Cd}=1-\mathrm{Cs} / \mathrm{Cd}$ ).

With this stress-strain analysis, we were able to separate preoperatively the patients into two groups. Group 2 showed the same $\mathrm{Cs} / \mathrm{Cd}$ value as group 1 for significantly lower left ventricular afterload (MWCS) levels. This finding suggests that patients in this group had a relatively poorer intrinsic shortening ability than those in group 1 , this fact being closely related to a poorer outcome after operation. In addition, the midwall circumferential stress was linearly and inversely related in both groups with the left ventricular midwall percentage fractional shortening $(1-\mathrm{Cs} / \mathrm{Cd})$. These findings are in close conceptual agreement with those of Borow et al in normal subjects $^{28}$ and suggest that the midwall circumferential stress to $\mathrm{Cs} / \mathrm{Cd}$ relation reflects the left ventricular intrinsic contractile state in chronic aortic regurgitation.

A controversial point in our results is the different degree of left ventricular hypertrophy in both groups of patients. Our data disagree with those of Gaasch et al, ${ }^{9}$ referring to the concept of "inadequate hypertrophy" in end stage chronic aortic regurgitation. These authors found that this ratio, as determined by echocardiography, was significantly lower in patients with chronic aortic regurgitation and a poor outcome after aortic valve replacement. These authors, as well as others, ${ }^{32}$ suggest that as the left ventricle dilates and, therefore, wall stress increases cardiac hypertrophy progresses to maintain wall stress within certain limits. In some cases, the ventricle dilates without an adequate hypertrophy, with a subsequent increase in stress and with the probability of developing irreversible left ventricular dysfunction.

In our view, this concept is questionable. Data from several authors ${ }^{73-35}$ show that the end systolic stress to end systolic volume index ratio is significantly higher in those patients with a better postoperative outcome, even though they relate to different pathological conditions. It is obvious that if two ventricles are indistinguishable with regard to end systolic volume and end systolic pressure, in order for the end systolic stress/end systolic volume index ratio 
to be higher in one patient, the $h: r$ ratio must be less in that same patient. On the other hand, other investigators have found no correlation between this last index and the postoperative course in chronic aortic regurgitation. ${ }^{125}$ In addition, there is some evidence suggesting that the postoperative course in chronic aortic regurgitation depends on total left ventricular mass rather than on relative hypertrophy, as measured by the h:r ratio; Krayenbuehl et al found that patients with chronic aortic regurgitation and a left ventricular mass $>180 \mathrm{~g} / \mathrm{m}^{2}$ were not able to normalise the left ventricular systolic function after successful aortic valve replacement, in contrast with those with a left ventricular mass $<180 \mathrm{~g} / \mathrm{m}^{2}$, who normalised their left ventricular systolic function after aortic valve replacement. ${ }^{36}$ Our results agree with these observations, suggesting that a very high degree of left ventricular hypertrophy precludes a good postoperative evolution in patients with chronic aortic regurgitation undergoing successful aortic valve replacement. We believe, however, that further studies are needed to resolve this controversial point.

The data presented in this study refer to a small group of patients and must, therefore, be regarded with caution. Future applications of this analysis to a larger number of patients should allow us to define its sensitivity and specificity with a higher degree of accuracy.

\section{References}

1 Bonow RO, Rosing DR, Kent KM, Epstein SE. Timing of operation for chronic aortic regurgitation. Am $\mathfrak{f}$ Cardiol 1982; 50: 325-36.

2 Bolen JL, Holloway EL, Zener JC, Harrison DC, Alderman EL. Evaluation of left ventricular function in patients with aortic regurgitation using afterload stress. Circulation 1976; 53: 132-8.

3 Bonow RO, Borer JS, Rosing DR, et al. Preoperative exercise capacity in symptomatic patients with aortic regurgitation as a predictor of postoperative left ventricular function and long-term prognosis. Circulation 1980; 62: 1280-90.

4 Mirsky I, Henschke C, Hess OM, Krayenbuehl HP. Prediction of postoperative performance in aortic valve disease. Am F Cardiol 1981; 48: 295-303.

5 Mehmel HC, Mazzoni S, Krayenbuehl HP. Contractility of the hypertrophied human left ventricle in chronic pressure and volume overload. Am Heart $\mathcal{F}$ 1975; 90: 236-40.

6 Johnson AD, Alpert JS, Francis GS, Vieweg VR, Ockene I, Hagan AD. Assessment of left ventricular function in severe aortic regurgitation. Circulation 1976; 54: 9759.

7 Osbakken M, Bove AA, Spann JF. Left ventricular function in chronic aortic regurgitation with reference to end-systolic pressure, volume and stress relations. $A m \mathcal{F}$ Cardiol 1981; 47: 193-8.
8 Henry WL, Bonow RO, Borer JS, et al. Observations on the optimum time for operative intervention for aortic regurgitation. 1. Evaluation of the results of aortic valve replacement in symptomatic patients. Circulation 1980; 61: 471-83.

9 Gaasch WH, Andrias CW, Levine HJ. Chronic aortic regurgitation: the effect of aortic valve replacement on left ventricular volume, mass and function. Circulation 1978; 58: 825-36.

10 Clark RD, Korcuska K, Cohn K. Serial echocardiographic evaluation of left ventricular function in valvular disease, including reproducibility guidelines for serial studies. Circulation 1980; 62: 564-75.

11 Sandler H, Dodge HT. The use of single plane angiocardiograms for the calculation of left ventricular volume in man. Am Heart f 1968; 75: 325-34.

12 Almeida Vergara P, Córdoba Polo M, López Minguez JR, Sokolowski Filip M, de Rábago González P. Localización del centro geométricó ventrículo izquierdo y sus aplicaciones a la angiocardiografia cuantitativa. Rev Esp Cardiol 1982; 35: 265-9.

13 Trenouth RS, Phelps NC, Neill WA. Determinants of left ventricular hypertrophy and oxygen supply in chronic aortic valve disease. Circulation 1976; 53: 644 50.

14 Hugenholtz PG, Kaplan E, Hull E. Determination of left ventricular wall thickness by angiocardiography. Am Heart f 1968; 78: 513-22.

15 Mirsky I. Left ventricular stress in the intact human heart. Biophys f 1969; 9: 189-208.

16 Bonow RO, Rosing DR, McIntosh CL, et al. The natural history of asymptomatic patients with aortic regurgitation and normal left ventricular function. Circulation 1983; 68: 509-17.

17 Henry WL, Bonow RO, Rosing DR, Epstein SE. Observations on the optimum time for operative intervention for aortic regurgitation. 2. Serial echocardiographic evaluation of asymptomatic patients. Circulation 1980; 61: 484-95.

18 McDonald IG, Jelinek VM. Serial M-mode echocardiography in severe chronic aortic regurgitation. Circulation 1980; 62: 1291-6.

19 Toussaint C, Cribier A, Cazor JL, Soyer R, Letac B. Hemodynamic and angiographic evaluation of aortic regurgitation 8 and 27 months after aortic valve replacement. Circulation 1981; 64: 456-63.

20 Burggraf GW, Craige E. Echocardiographic studies of left ventricular wall motion and dimensions after valvular heart surgery. Am $\mathcal{F}$ Cardiol 1975; 35: 473-80.

21 Venco A, St John Sutton MG, Gibson DG, Brown DJ. Non-invasive assessment of left ventricular function after correction of severe aortic regurgitation. Br Heart $\mathcal{F}$ 1976; 38: 1324-31.

22 Hirschfeld JW Jr, Epstein SE, Roberts AJ, Glancy DL, Morrow AG. Indices predicting long-term survival after valve replacement in patients with aortic regurgitation and patients with aortic stenosis. Circulation 1974; 50: 1190-9.

23 Bristow JD, Kremkau EL. Hemodynamic changes after valve replacement with Starr-Edwards prostheses. Am $\mathcal{F}$ Cardiol 1975; 35: 716-24.

24 Grossman W, Braunwald E, Mann T, McLaurin LP, 
Green LH. Contractile state of the left ventricle in man as evaluated from end-systolic pressure-volume relations. Circulation 1977; 56: 845-52.

25 Cunha CLP, Giuliani ER, Fuster V, Seward JB, Brandenburg RO, McGoon DC. Preoperative M-mode echocardiography as a predictor of surgical resuits in chronic aortic insufficiency. 7 Thorac Cardiovasc Surg 1980; 79: 256-65.

26 Borow KM, Green LH, Mann T, et al. End-systolic volume as a predictor of postoperative left ventricular performance in volume overload from valvular regurgitation. Am f Med 1980; 68: 655-63.

27 Clark DG, McAnulty JH, Rahimtoola SH. Valve replacement in aortic insufficiency with left ventricular disfunction. Circulation 1980; 61: 411-21.

28 Borow KM, Green LH, Grossman W, Braunwald E. Left ventricular end-systolic stress-shortening and stress-length relations in humans. Normal values and sensitivity to inotropic state. Am $\mathcal{F}$ Cardiol 1982; 50: 1301-8.

29 Mehmel HC, Stockins B, Ruffmann K, Olshausen K, Schuler G, Kübler W. The linearity of the end-systolic pressure-volume relationship in man and its sensitivity for assessment of left ventricular function. Circulation 1981; 63: 1216-22.

30 Nivatpumin T, Katz S, Scheuer J. Peak left ventricular systolic pressure/end-systolic ratio: a sensitive detector of left ventricular disease. Am $\mathcal{F}$ Cardiol 1979; 43: 969-74.

31 Marsh JD, Green LH, Wynne J, Cohn PF, Grossman W. Left ventricular end-systolic pressure-dimension and stress-length relations in normal human subjects. $A m \mathcal{J}$ Cardiol 1979; 44: 1311-7.

32 Kumpuris AG, Quinones MA, Waggoner AD, Kanon DJ, Nelson JG, Miller RR. Importance of preoperative hypertrophy, wall stress and end-systolic dimension as echocardiographic predictors of normalization of left ventricular dilatation after valve replacement in chronic aortic insufficiency. Am $\mathcal{F}$ Cardiol 1982; 49: 1091-100.

33 Carabello BA, Nolan SP, McGuire LB. Assessment of preoperative left ventricular function in patients with mitral regurgitation. Value of the end-systolic wall stress-end-systolic volume ratio. Circulation 1981; 64: 1212-7.

34 Carabello BA, Gash A, Mayers D, Spann JF. Normal left ventricular systolic function in adults with atrial septal defect and left heart failure. Am $\mathcal{F}$ Cardiol 1982; 49: 1868-73.

35 Hirota Y, Furubayashi K, Kaku K, et al. Hypertrophic nonobstructive cardiomyopathy: a precise assessment of hemodynamic characteristics and clinical implications. Am $\mathcal{F}$ Cardiol 1982; 50: 990-7.

36 Krayenbuehl HP, Hess OM, Schneider J, Turina M. Physiologic or pathologic hypertrophy. Eur Heart $\mathcal{f}$ 1983; 4 (suppl A): 29-34. 